\title{
Approach-avoidance: Potency in psychological research
}

\author{
JOHN B. GORMLY \\ Rutgers University, New Brunswick, New Jersey 08903 \\ and \\ ANNE V. GORMLY \\ Trenton State College, Trenton, New Jersey 08625
}

\begin{abstract}
Women heard another person state attitudes that were either in high agreement or high disagreement with their own attitudes. The potency of an approach-avoidance dependent variable was compared with traditional dependent variables for this situation, ratings of interpersonal attraction. Eighty-five percent of those hearing high agreement volunteered to return to the laboratory to continue participation in the study at a later time. Nobody who heard high disagreement volunteered to return. This difference between the two treatment conditions was considerably greater than the difference for ratings of attractiveness. It was concluded that the increased potency of the approach-avoidance measure came from its importance to the subjects and that approach-avoidance would be a good measure to use in comparing different predictions from the several theoretical positions that attempt to account for the effects of agreement and disagreement.
\end{abstract}

Behaving selectively is crucial to the well-being of all organisms. This process includes selective attention to the environment and selective responding from a vast repertoire of potential performance. Understanding the processes of behaving selectively is the metagoal of all areas within psychology; it is the paradigm, in Kuhn's (1962) use of the word, that identifies psychology as a scientific discipline.

The most global element of behaving selectively is the direction of the organism with respect to some aspect of the environment: approach and avoidance. Not surprisingly, several of the early theoretical models of behavior were based on experimental investigations of approach-avoidance or their interaction, conflict (Brown, 1948; Miller, 1944; Mowrer, 1948). These concerns were important for practical, clinical treatment of emotional-behavioral disturbances of people and are underscored today by the growing interest in assertiveness training and desensitization techniques.

In view of the central role that approach and avoidance have for the survival of living beings, a reasonable assumption is that the simple, direct measurement of approach and avoidance would be a powerful dependent measure in research. The study that follows provides an example of this potency.

Research was conducted using a standard procedure for studying the effects of receiving agreement or dis-

Requests for reprints can be sent to John Gormly, Department of Psychology, Rutgers University, New Brunswick, New Jersey 08903, or to Anne Gormly, Department of Psychology, Trenton State College, Trenton, New Jersey 08625. agreement (Baugher \& Gormly, 1975; Clore \& Gormly, 1974; Gormly, 1974), in which the traditional dependent measures were compared with a direct measure of approach-avoidance. Subjects were told that they would hear another student state her attitudes toward a variety of topics, and based on this information, subjects were to make judgments about personality characteristics of the other person, a confederate in the study. The attitudes that the confederate presented were contrived so that she was in high agreement with the attitudes of 20 of the subjects and in high disagreement with the remaining 20 subjects. After this interaction with the confederate, the subjects were given a set of questionnaires to complete privately; they were the dependent measures. Two of them were traditional, indirect measures of attraction (approach), Byrne's (1971) Interpersonal Judgment Scale and the Evaluative-Behavioral Measure of Attraction (Gormly, Gormly, \& Johnson, 1971). Another, the direct measure of approach and avoidance, asked the subjects if they would volunteer to return to the laboratory to participate further in the study.

\section{METHOD}

\section{Subjects}

Forty female undergraduates from a large state university participated in this study. They were students in the first semester of the introductory course in psychology, and they participated in this study to fulfill a requirement of the course. Because of the availability of two experienced female accomplices, only women were included in the study. The sex of the confederate and that of the subject were, therefore, always the same. 
War (check one)

I strongly feel that war is sometimes necessary to solve world problems. I feel that war is sometimes necessary to solve world problems.

I feel that perhaps war is sometimes necessary to solve world problems.

I feel that perhaps war is never necessary to solve world problems.

I feel that war is never necessary to solve world problems.

I strongly feel that war is never necessary to solve world problems.

Figure 1. Example from the attitude survey.

\section{Questionnaires}

Five questionnaires were used in this study: a survey of attitudes, two measures of interpersonal attraction, a survey of physical and personality characteristics, and a request for volunteers. The survey of attitudes consisted of 12 topics of high interest to college students: striving for the respect of others, birth control, the necessity of wars for solving world problems, fear of the future, the significance of beliefs about eternal life, state income tax, expression of emotions in public, use of the death penalty, world communism as a threat to U.S. security, legalization of marijuana, the consequences of preparedness for war, and the American way of life. There were six options for each topic, three intensities of "pro" the topic and three intensities of "con." The topics and alternatives were in the general form shown in Figure 1.

The second questionnaire was the Evaluative-Behavioral Attraction Measure, developed by Gormly et al. (1971). This is a six-item questionnaire for rating the interpersonal attractiveness of another person. Three scales are used for evaluative descriptions (e.g., pleasant-unpleasant), and three scales are used for indicating the degree of intimacy that might be permitted (e.g. "Would you accept this person as a member of your social group?"). There are six alternatives for each of the six items.

The third questionnaire was the Interpersonal Judgment Scale, described by Byrne (1971). This scale has the subject rate another on two 7-point dimensions: an estimate of how much she likes or dislikes the other person and whether or not she would like to be the person's partner in another experiment.

The fourth questionnaire was included simply to make the experimental procedure correspond to the stated purpose of the study, making judgments about the personality of the other person (the confederate).

The final questionnaire consisted of the following statementquestion: "Would you be willing to come back at a later time this semester and take the part of the person presenting her attitudes? We need volunteers, and we are unable to pay you or to give you additional course credit, but we would appreciate your assistance. We can pick a time to fit your schedule. All you have to do is come here for personality assessment and then present your attitudes to a few other students."

The subjects were then asked to indicate their willingness to volunteer by writing "yes" or "no," and if "yes," to provide information about how we could contact them. This was the direct approach-avoidance measure for this study.

\section{Procedure}

A male experimenter met the subject when she arrived at the laboratory. He informally explained the purpose and format of the study to her. Then she was asked to read the following description of the study: "We are investigating how people make judgments about other people. You will meet another person who is being paid for her work in this study. We have done an extensive job of assessing social and personality characteristics of this person.
"We want to know how accurate you are in judging personality characteristics, knowing only information about the other person's social attitudes. Your opinions will be compared for accuracy against our own personality assessment data.

"We would like you to respond to a questionnaire of social attitudes. All the information we receive from you will be coded by number-it is completely confidential-and will be used for research purposes only."

When the subject finished reading the instructions, she was given the 12-item attitude questionnaire described earlier in this report. When she was finished, the experimenter brought her to another room, in which she met one of the confederates. Both confederates were students at the university. They did not know any of the subjects, and they did not know the experimental treatment the subject received, high-percent agreement or highpercent disagreement.

The experimenter had the survey of attitudes completed by the subject attached to his clipboard. The confederate also had a copy of the survey in her hands. The subject and the confederate were seated at opposite sides of a table, facing each other, and the experimenter was standing slightly to the rear of the subject. He went through the 12 attitude topics, asking the confederate to state the position in the survey that best represented her attitude for each topic. The alternative spoken by the accomplice was determined by a discreet hand signal from the experimenter; he selected positions such that the subject heard either agreement on 9 of the 12 topics (high-agreement treatment) or disagreement on 9 of the 12 topics (highdisagreement treatment). The proportion of agreements/ disagreements was the same for the first four topics, the middle four topics, and the last four topics. To reduce suspicion, agreement and disagreement are created using the constant discrepancy method (Byrne, 1971). In this method, the accomplice never gives exactly the same response as the subject.

When the 12 th attitude topic was stated, the experimenter thanked the confederate for her participation, and she left. The experimenter then gave the subject the four remaining questionnaires; the question about volunteering was the last in the set. The experimenter told the subject to complete the questionnaires, to put them in an envelope that was provided, and to come into the next room when she was finished. The experimenter left her alone to complete the questionnaires. When the subject came into the first room, he thanked her for participation and asked her what she thought the study would find out, and she left.

\section{RESULTS}

None of the subjects gave any indication that they were suspicious about the true purpose of the study.

The Evaluative-Behavioral Attraction Measure produces scores that can range from 6 to 36, with the midpoint of the scores (neutral) as 21; higher scores represent increased attraction. The mean and standard deviation for the agreement condition were 26.5 and 4.1. The mean and standard deviation for the disagreement condition were 21.8 and $3.9[\mathrm{t}(38)=3.6, \mathrm{p}<.01]$. Similarly, the Interpersonal Judgment Scale produces scores that can range from 2 to 14 , with the midpoint at 8 . The mean and standard deviation for the agreement condition were 11.2 and 2.2. The mean and standard deviation for the disagreement condition were 9.0 and $1.9[\mathrm{t}(38)=3.5, \mathrm{p}<.01]$. 
Seventeen of the 20 subjects receiving the agreement condition volunteered to return to the study, for no money or credit. Nobody from the disagreement condition volunteered to return, 0 of 20 . This difference is substantial and highly significant $\left(\chi^{2}=29\right)$.

\section{DISCUSSION}

In this study, subjects were presented a fundamental aspect of behaving selectively, the choice of approach (volunteer to return to the laboratory) or avoidance (not volunteering). Obviously, this dependent measure was much more sensitive to the experimental treatment, agreement or disagreement, than were the other dependent measures, ratings of attraction. The difference would seem to be related to the importance of each measure for the subject; ratings of evaluative characteristics of the confederate have minimal real-world significance for the subject.

An inspection of the ratings supports this position regarding the low importance of the ratings to the subjects. Although the range of scores on the Evaluative-Behavioral Attraction Measure is 31 points, the difference between the two groups in this study was only 4.7 , and the mean for the group that received high disagreement was approximately at the neutral point of the scale. Similar data were found for the Interpersonal Judgment Scale.

The substantial results found with the approach-avoidance measure point out two phenomena: first, the sensitivity of approach-avoidance as a dependent measure and, second, the power of the treatment, agreement vs. disagreement. Why are people so much affected by hearing another state opinions that agree or disagree with their own? There exists no shortage of theoretical positions attempting to account for the effects of agreement or disagreement on people. These positions include the affect-reinforcement model (Byrne \& Clore, 1967), balance theory (Heider, 1958), dissonance theory (Festinger, 1957), information integration theory (Anderson, 1971), and rewardsof-interaction position (Berscheid \& Walster, 1969). While it is possible that all of these positions are equally good in accounting for the impact of agreement and disagreement, it is more likely that one or some are better than others. There have been a few studies that have attempted to test the differential utilities of the theoretical positions by varying the conditions in which the agreement or disagreement occurred (Baugher \& Gormly, 1975 Gormly, 1974; Kaplan \& Anderson, 1973). It is likely, however, that the insensitivity of the dependent measure has been an impediment to effective comparisons of the theoretical positions and that an approach-avoidance measure would be useful for reducing the number of theoretical accounts for the effects of agreement and disagreement.

\section{REFERENCES}

Anderson, N. H. Integration theory and attitude change. Psychological Review, 1971, 78, 171-206.

BaUgher, D. M., \& Gormly, J. Effects of personal competence on the significance of interpersonal agreement and disagreement: Physiological activation and social evaluations. Journal of Research in Personality, 1975, 9, 356-365.

Berscheid, E., \& Walster, E. Interpersonal attraction. Reading, Mass: Addison-Wesley, 1969.

Brown, J. S. Gradients of approach and avoidance responses and their relation to motivation. Journal of Comparative and Physiological Psychology, 1948, 41, 450-465.

Byrne, D. The attraction paradigm. New York: Academic Press, 1971.

Byrne, D., \& Clore, G. L. Effectance arousal and attraction. Journal of Personality and Social Psychology (Monograph), 1967, 6(Whole No. 638)

Clore, G. L., \& Gormly, J. B. Knowing, feeling, and liking: A psychophysiological study of attraction. Journal of Research in Personality, 1974, 8, 218-230.

Festinger, L. A. A theory of cognitive dissonance. Evanston, Ill: Row, Peterson, 1957.

GormLY, J. A comparison of predictions from consistency and affect theories for arousal during interpersonal disagreement. Journal of Personality and Social Psychology, 1974, 30, 658-663.

GormLy, J., GormLy, A., \& Johnson, C. Interpersonal attraction, competence, motivation, and reinforcement theory. Journal of Personality and Social Psychology, 1971, 19, 375-380.

HeIDER, F. The psychology of interpersonal relations. New York: Wiley, 1958.

Kaplan, M. F., \& Anderson, N. H. Information integration theory and reinforcement theory as approaches to interpersonal attraction. Journal of Personality and Social Psychology, 1973, 28, 301-312.

Kunn, T. The structure of scientific revolutions. Chicago: University of Chicago Press, 1962.

Mille R, N. E. Experimental studies of conflict. In J. M. Hunt (Ed.), Personality and the behavior disorders (Vol. 1). New York: Ronald Press, 1944.

Mowren, O. H. Learning theory and the neurotic paradox. American Journal of Orthopsychiatry, 1948, 18, 571-610.

(Received for publication April 20, 1981.) 